Article

\title{
Design, Synthesis and Biological Evaluation of Stilbene Derivatives as Novel Inhibitors of Protein Tyrosine Phosphatase 1B
}

\author{
Haibing He ${ }^{1}$, Yinghua Ge ${ }^{2}$, Hong Dai ${ }^{1, *}$, Song Cui ${ }^{1}$, Fei Ye ${ }^{1}$, Jia Jin ${ }^{2, *}$ and Yujun Shi ${ }^{1, *}$ \\ 1 College of Chemistry and Chemical Engineering, Nantong University, Nantong 226019, China; \\ hehaibing@ntu.edu.cn (H.H.); cuisong123@163.com (S.C.); yefei@zstu.edu.cn (F.Y.) \\ 2 College of Life Sciences, Zhejiang Sci-Tech University, Hangzhou 310018, China; geyinghua1992@163.com \\ * Correspondence: dai_hong@aliyun.com (H.D.); aukaukauk@163.com (J.J.); ntushyj@163.com (Y.S.); \\ Tel.: +86-571-8684-3199 (J.J.); +86-513-8501-2856 (H.D. \& Y.S.)
}

Academic Editor: Derek J. McPhee

Received: 26 October 2016; Accepted: 12 December 2016; Published: 16 December 2016

\begin{abstract}
By imitating the scaffold of lithocholic acid (LCA), a natural steroidal compound displaying Protein Tyrosine Phosphatase 1B (PTP1B) inhibitory activity, a series of stilbene derivatives containing phenyl-substituted isoxazoles were designed and synthesized. The structures of the title compounds were confirmed by ${ }^{1} \mathrm{H}-\mathrm{NMR},{ }^{13} \mathrm{C}-\mathrm{NMR}$ and HRMS. Activities of the title compounds were evaluated on PTP1B and the homologous enzyme TCPTP by using a colorimetric assay. Most of the target compounds had good activities against PTP1B. Among them, compound $29\left(\mathrm{IC}_{50}=0.91 \pm 0.33 \mu \mathrm{M}\right)$, characterized by a 5-(2,3-dichlorophenyl) isoxazole moiety, exhibited an activity about 14-fold higher than the lead compound LCA and a 4.2-fold selectivity over TCPTP. Compound 29 was identified as a competitive inhibitor of PTP1B with a $K_{\mathrm{i}}$ value of $0.78 \mu \mathrm{M}$ in enzyme kinetic studies.
\end{abstract}

Keywords: protein tyrosine phosphatase 1B (PTP1B); lithocholic acid; stilbene; inhibitor

\section{Introduction}

Protein tyrosine phosphatases (PTPs) are a superfamily of enzymes involved in crucial cellular signalling mechanisms by controlling the phosphorylation levels of specific tyrosine residues in peptides and proteins which regulate many cellular functions, such as cell proliferation, survival, metabolism, adhesion and migration. Among the PTPs so far identified, the cytosolic protein tyrosine phosphatase 1B (PTP1B) was the first phosphatase to be isolated and is therefore the most widely studied [1-4]. A large body of experimental data acquired from in vivo studies on humans and PTP1B-knockout mice has identified PTP1B as a major negative regulator of both insulin and leptin signals. Consequently, inhibiting of PTP1B was considered to be a potential therapeutics for treating Type 2 diabetes and obesity by enhance insulin sensitivity and resistance to obesity [5-8]. Moreover, it is worth noting that PTPs share a high degree of structural conservation in the active site, especially for T-cell protein tyrosine phosphatase (TCPTP), which has a sequence identity of about $74 \%$ in the catalytic domains with PTP1B [9]. There is always a challenge for the potent PTP1B inhibitors to keep good selectivity over TCPTP in the same time [10].

In the past decades, several steroids and their derivatives were found to possess moderate to good PTP1B inhibitory activities, such as lithocholic acid (LCA, 1, Figure 1) [11], claramine (3) [12] and trodusquemine (2) [13], the first PTP1B inhibitor for the treatment of diabetes in clinical trials. However, risk of the hormonal effect of steroids and their derivatives always cannot be neglected. Years ago, diethylstilbestrol (4) was developed as a mimic and alternative drug for estradiol (5) [14], which indicated the fact that the stilbene moiety could be an ideal replacement of the steroid skeleton 
in drug design when use the "scaffold hopping" method [15]. Additionally, stilbene is a common moiety found in many natural products endowed with antibacterial, antioxidative, antiproliferative or antidiabetic activities, such as resveratrol (6), pinosylvin (7) and piceatannol (8) [16-19].

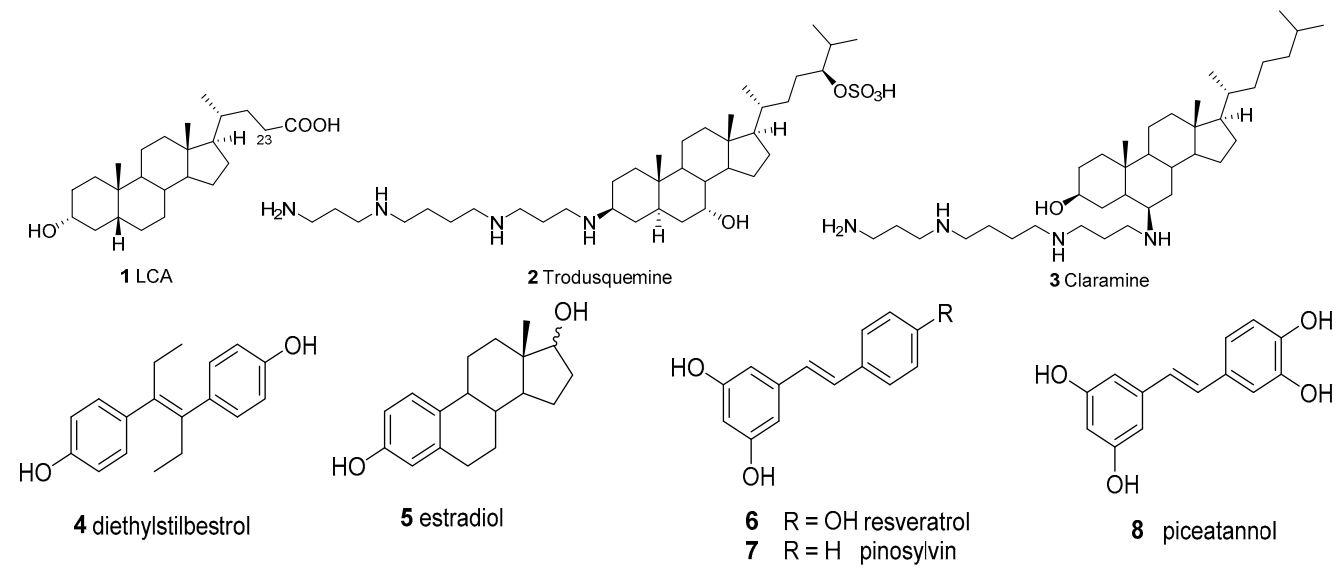

Figure 1. Steroids 1 3 reported as PTP1B inhibitors and stilbene derivatives 4 8.

In a previous report we disclosed that the introduction of phenyl-substituted heterocyclic rings, such as pyrazole, oxazole, isoxazole and thiazoles, into the ring A on LCA would improve the inhibitory activity against PTP1B. On the other hand, it has also been verified that the 23-COOH of LCA was irreplaceable for maintaining the activities against PTP1B [11]. Based on the views above, we tentatively designed a class of stilbene derivatives, as shown in Figure 2, which was characterized by a phenyl-substituted isoxazole linked to the stilbene scaffold by an ether bond. In order to search for the optimized phenyl isoxazole moiety, at the very beginning, we designed and synthesized four mimics (compounds 15, 16, 17 and 18), containing 3-phenyl-4-isoxazolyl-, 5-methyl-3-phenyl-4-isoxazolyl-, 5-phenyl-4-isoxazolyl and 5-phenyl-3-isoxazolyl groups, respectively, and evaluated their inhibitory effects against PTP1B. As a result, compound 18 was found to have the highest activity to PTP1B $\left(\mathrm{IC}_{50}=6.33 \pm 1.02 \mu \mathrm{M}\right)$. Then a series of its derivatives 19 30 with different groups on the phenyl ring $C$ was synthesized and evaluated.

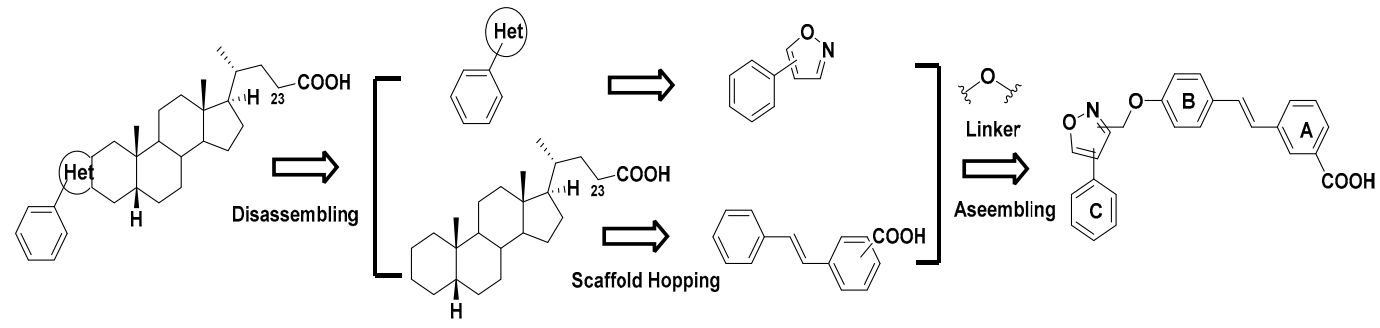

Figure 2. The design of the title compounds.

\section{Results and Discussion}

\subsection{Chemistry}

As shown in Scheme 1, target compounds 15 30 were all prepared by condensation of the stilbene intermediate 14 and the corresponding chloromethyl isoxazole 15c 30c in DMSO with $\mathrm{Cs}_{2} \mathrm{CO}_{3}$ as the acid-binding agent, followed by hydrolysis in $\mathrm{KOH}$ solution and acidification with hydrochloric acid. Starting from 3-methylbenzoate (9), the key intermediate 14 was synthesized in five steps including bromination [20], Arbuzov reaction, Wittig-Horner reaction [21], demethylation [22] and selective methylation. At the beginning, by using $\mathrm{PPh}_{3}$, a Wittig reaction was employed to synthesize the 
compound 12, giving a mixture of cis- and trans-products with a ratio of about 1:2. Alternatively, the Wittig-Horner reaction gave a satisfactory result, unexpectedly accompanied by the hydrolysis of methyl ester due to the strong basicity of $t$-BuOK. In addition, intermediate 10 was obtained conveniently through a routine method using NBS as the brominating agent and AIBN as the radical initiator. Since deprotection of the methyl of 12 in $\mathrm{BBr}_{3} / \mathrm{DCM}$ led to a mass of by-products, the reaction was carried out successfully in a mixture of $\mathrm{AlCl}_{3}$ and $\mathrm{Et}_{3} \mathrm{~N}$. Before the condensation of phenolic hydroxyl and the chlorinated intermediates 15c 30c, the carboxyl group on the phenyl A ring of 13 was selectively protected by MeI. Slight methylation of the phenolic hydroxyl group occured in the same time.

Compounds 15c 30c were synthesized from the corresponding methyl carboxylates 15a 30a via reduction by $\mathrm{LiAlH}_{4}$ and chlorination with $\mathrm{SOCl}_{2}$ in $\mathrm{DCM}$. Intermediates from the above two steps were used directly without any purification. Compounds 15a, 16a and 17a were prepared according to the reported methods [23-25]. By reference to Kamal's report, compounds 18a 30a were synthesized from the corresponding substituted acetophenones [26].

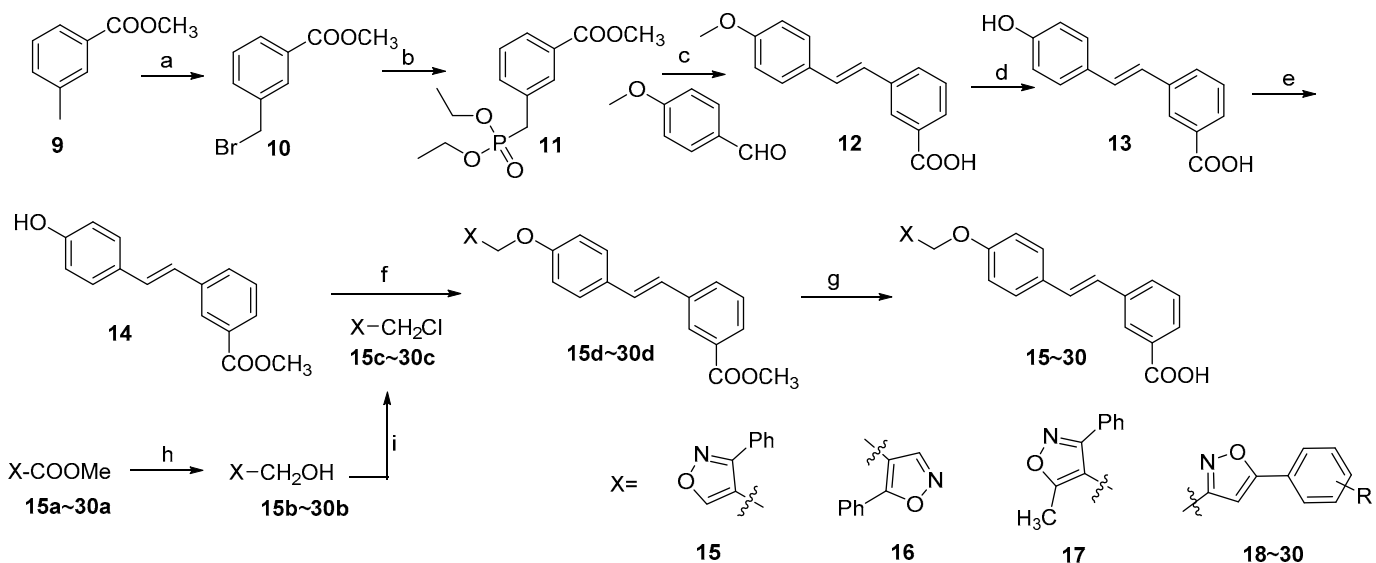

Scheme 1. Synthesis of compounds 10 30. Reagents and conditions: (a) $\mathrm{CCl}_{4}, \mathrm{NBS}$, reflux, $6 \mathrm{~h}$; (b) $\mathrm{P}(\mathrm{OEt})_{3}, 160{ }^{\circ} \mathrm{C}$; (c) $t$-BuOK, THF, $0{ }^{\circ} \mathrm{C} \sim$ r.t., overnight; (d) $\mathrm{AlCl}_{3}, \mathrm{Et}_{3} \mathrm{~N}, 60{ }^{\circ} \mathrm{C} \sim 90{ }^{\circ} \mathrm{C}, 18 \mathrm{~h}$; (e) $\mathrm{MeI}, \mathrm{K}_{2} \mathrm{CO}_{3}$, acetone, $60{ }^{\circ} \mathrm{C}, 15 \mathrm{~h}$; (f) $\mathrm{Cs}_{2} \mathrm{CO}_{3}$, DMSO, $65{ }^{\circ} \mathrm{C}, 8 \mathrm{~h}$; (g) $\mathrm{KOH}, \mathrm{H}_{2} \mathrm{O}, 65{ }^{\circ} \mathrm{C}, 6 \mathrm{~h}$; (h) $\mathrm{LiAlH}_{4}, 0{ }^{\circ} \mathrm{C} \sim$ r.t., $4 \mathrm{~h}$; (i) $\mathrm{SOCl}_{2}, \mathrm{DCM}, 45^{\circ} \mathrm{C}, 8 \mathrm{~h}$.

\subsection{In Vitro Biological Evaluation}

All of the title compounds were assayed on the enzyme PTP1B in vitro. In compounds 15 18, the phenyl position on the isoxazole ring caused huge differences in the inhibition against PTP1B. As shown in Table 1, both compounds 15 and 17, characterized by a 3-phenyl-4-isoxazole moiety, exhibit moderate activities against the enzyme. Meanwhile, the 5-phenyl-4-isoxazole compound 16 $\left(\mathrm{IC}_{50}=16.2 \pm 4.52 \mu \mathrm{M}\right)$ also has similar activity, while another 5-phenyl compound, 18, exhibits a much higher activity $\left(\mathrm{IC}_{50}=6.33 \pm 1.02 \mu \mathrm{M}\right)$ due to the different position of the isoxazole ring linked to the phenyl $\mathrm{B}$ ring. This result inspired us to further investigate the substituents on phenyl $\mathrm{C}$ and their effects on the activities against PTP1B. On the other hand, as expected, methylation of the carboxyl of 18 led to an obvious decrease on PTP1B inhibition.

Derivatives of 18 and their activities against PTP1B and TCPTP are listed in Table 2. For substituents at the 2-position of phenyl C, the electron-withdrawing chlorine atom (compound 19) was beneficial to the activity when compared to an electron-donating methoxy (compound 20). 3-subtituents also affect the activities remarkably. Compounds containing 3-Cl (21) and 3- $\mathrm{Br}$ (23) exhibit obvious inhibition to PTP1B, whereas a 3-F leads to a dramatic decrease in activity. $\mathrm{NO}_{2}\left(25, \mathrm{IC}_{50}=2.05 \pm 0.54 \mu \mathrm{M}\right)$ seems to be the optimal 3-substituent among the synthesized compounds, giving an activity 3-fold higher than compound that of 18. In addition, when the 3-position is occupied by a methyl group, the resulting compound 24 still shows good inhibitory effect against the enzyme $\left(\mathrm{IC}_{50}=3.68 \pm 1.12 \mu \mathrm{M}\right)$. 
Table 1. The structures of compounds $15,16,17,18,18 \mathrm{~d}$ and their $\mathrm{IC}_{50}$ values against PTP1B.

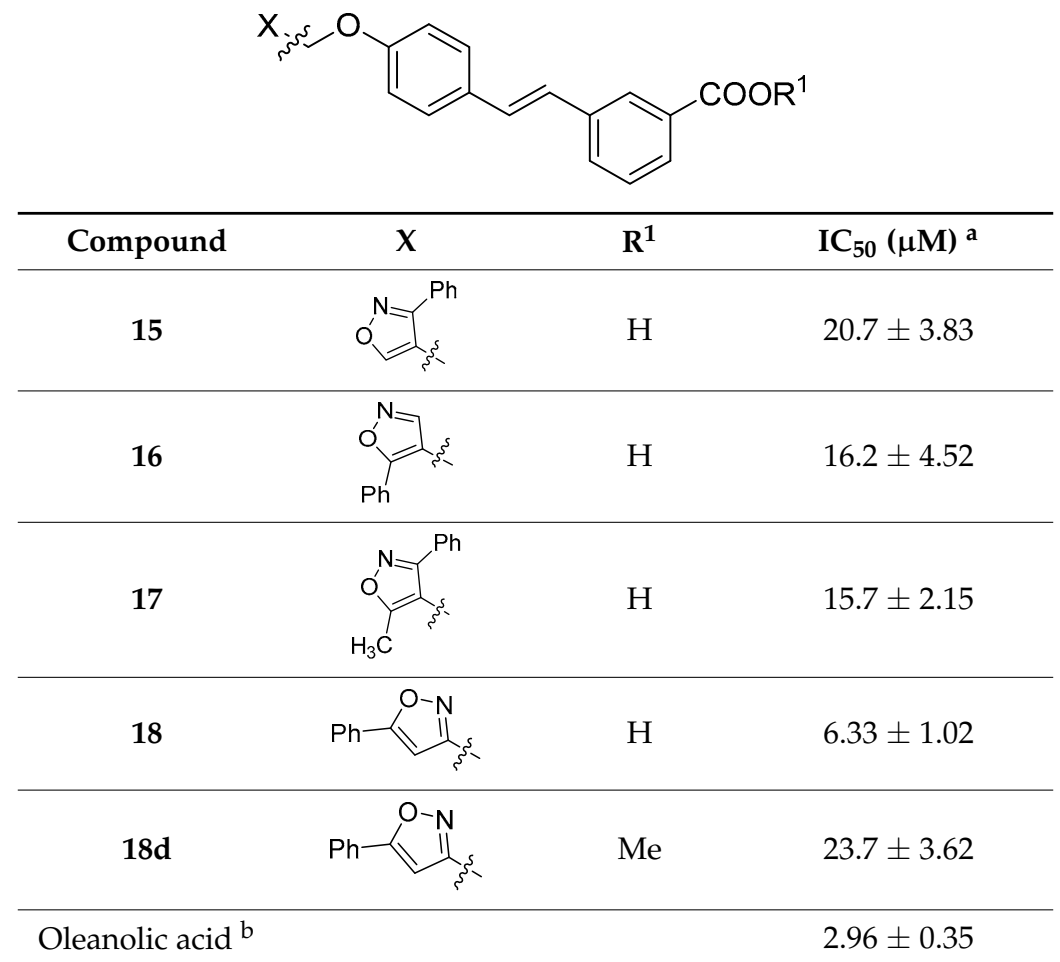

${ }^{\text {a }} \mathrm{IC}_{50}$ values were determined by regression analyses and expressed as means \pm SD of three replications; ${ }^{b}$ Positive control.

Table 2. The structures of compounds 18 30 and their $\mathrm{IC}_{50}$ values against PTP1B and TCPTP.

\begin{tabular}{|c|c|c|c|c|}
\hline \multirow{2}{*}{ Compound } & \multirow{2}{*}{$\mathbf{R}$} & \multicolumn{2}{|c|}{$\mathrm{IC}_{50}(\mu \mathrm{M})^{\mathrm{a}}$} & \multirow{2}{*}{ ТСРТР/РТР1В } \\
\hline & & PTP1B & ТСРТР & \\
\hline 18 & $\mathrm{H}$ & $6.33 \pm 1.33$ & $9.58 \pm 0.33$ & 1.5 \\
\hline 19 & $2-\mathrm{Cl}$ & $1.75 \pm 0.82$ & $36.15 \pm 3.82$ & 20.7 \\
\hline 20 & 2-OMe & $7.66 \pm 1.05$ & $>40$ & 5.3 \\
\hline 21 & $3-\mathrm{Cl}$ & $5.37 \pm 1.53$ & $7.58 \pm 1.32$ & 1.4 \\
\hline 22 & $3-\mathrm{F}$ & $>20$ & $>40$ & $-c$ \\
\hline 23 & $3-\mathrm{Br}$ & $9.85 \pm 2.04$ & $>40$ & 4.1 \\
\hline 24 & 3-Me & $3.68 \pm 1.12$ & $18.91 \pm 1.18$ & 5.1 \\
\hline 25 & $3-\mathrm{NO}_{2}$ & $2.05 \pm 0.54$ & $13.25 \pm 1.70$ & 6.5 \\
\hline 26 & $4-\mathrm{Me}$ & $3.56 \pm 0.28$ & $7.67 \pm 0.35$ & 2.2 \\
\hline 27 & 4-OMe & $2.23 \pm 0.51$ & $8.02 \pm 0.99$ & 3.6 \\
\hline 28 & 4-F & $3.34 \pm 0.81$ & $5.19 \pm 0.31$ & 1.6 \\
\hline 29 & $3,4-\mathrm{Cl}_{2}$ & $0.91 \pm 0.33$ & $3.78 \pm 0.22$ & 4.2 \\
\hline 30 & $3,4-\mathrm{F}_{2}$ & $1.22 \pm 0.48$ & $6.02 \pm 1.13$ & 4.9 \\
\hline Lithocholic acid & & $12.54 \pm 2.51$ & $20.95 \pm 3.66$ & 1.7 \\
\hline Oleanolic acid ${ }^{\mathrm{d}}$ & & $2.71 \pm 0.19$ & $6.12 \pm 0.15$ & 2.3 \\
\hline
\end{tabular}

\footnotetext{
${ }^{a} \mathrm{IC}_{50}$ values were determined by regression analyses and expressed as means $\pm \mathrm{SD}$ of three replications; b TCPTP/PTP1B, the ratio of $\mathrm{IC}_{50}$ of TCPTP and PTP1B; ${ }^{\circ}$ "“", none accurate value was calculated;

d Positive control.
}

The derivatives present good tolerance of 4-substituents on the phenyl C ring, since compounds 26 (4-Me), 27 (4-OMe) and 28 (4-F) have similar activities against PTP1B. Amazingly, the di-substituted 
compounds, either dichloro (29) or difluoro (30) exhibited the highest inhibitory activities against the enzyme among all the title compounds. Most of all, compound 29 has an activity $\left(\mathrm{IC}_{50}=0.91 \pm 0.33 \mu \mathrm{M}\right)$ about 14-fold higher than the lead compound LCA, which prompts us to further study on its structure modification and biological activity. However, as shown in Table 2, it is unfortunate that most of the compounds also exhibit some activities against TCPTP, except for compounds 20, 22 and 23. The selectivities against PTP1B and TCPTP vary a lot, from 1.4 to 22.9. Among the five compounds most potent against PTP1B (19, 25, 27, 29 and 30), compound 19 has the best selectivity (TCPTP/PTP1B = 20.7) while compound 29 has about a 4-fold selectivity over TCPTP. These two compounds are promising for further study as anti-diabetes drugs.

\subsection{Enzyme Kinetic Study}

In order to determine the inhibition mode of the title compounds, the most active compound 29 was selected for a PTP1B enzyme kinetic study using the Michaelis-Menten equation. As shown in Figure 3, the $V_{\max }$ value remained constant while the $K_{\mathrm{m}}$ value increased with the mounting compound concentration, indicating that $\mathbf{2 9}$ was a competitive PTP1B inhibitor, which was further confirmed by a Lineweaver-Burk plot (Figure 3c). The calculated inhibitory constant $K_{\mathrm{i}}$ of compound 29 was $0.78 \mu \mathrm{M}$.

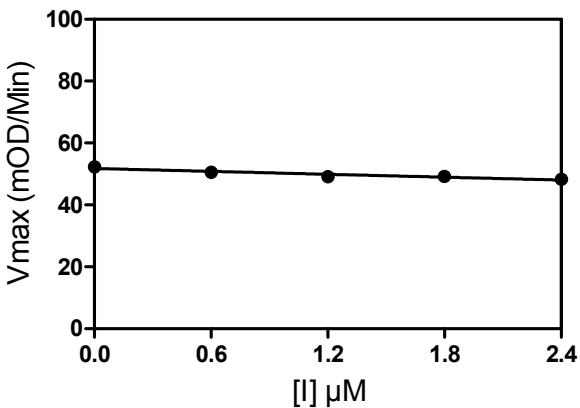

(a)

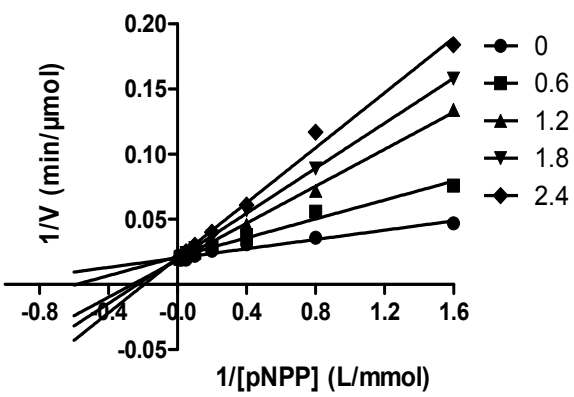

(c)

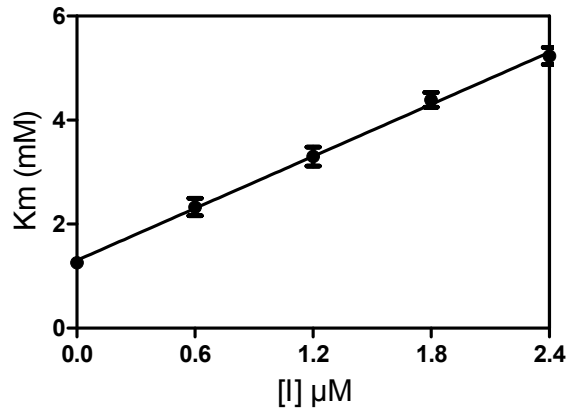

(b)

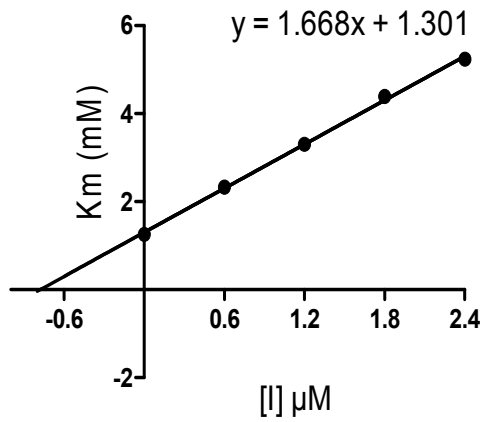

(d)

Figure 3. Characterization of 29 to PTP1B. $(\mathbf{a}, \mathbf{b})$ At various fixed concentrations of 29 the initial velocity was determined with various concentrations of pNPP; (c) Typical competitive inhibition of 29 shown by Lineweaver-Burk plot; (d) Linear replot of $K_{m}$ versus the inhibitor (29) concentration [I].

\section{Experimental Section}

\subsection{Chemsitry}

\subsubsection{General Information}

All reagents were chemically pure and solvents were dried according to standard methods. The ${ }^{1} \mathrm{H}-\mathrm{NMR}$ and ${ }^{13} \mathrm{C}-\mathrm{NMR}$ spectra were obtained on an AV400 spectrometer $\left(400 \mathrm{MHz},{ }^{1} \mathrm{H} ; 100 \mathrm{MHz}\right.$, ${ }^{13} \mathrm{C}$, Bruker, Billerica, MA, USA) in $\mathrm{CDCl}_{3}$ with tetramethylsilane as the internal standard. The melting points were determined on an X-4 binocular microscope melting point apparatus (Beijing Tech 
Instrument Co., Beijing, China) and are uncorrected. High-resolution mass data were obtained on a Micromass TOF II spectrometer (Micromass, Cary, NC, USA). The reactions were monitored by analytical thin-layer chromatography (TLC) carried out on silica gel $\mathrm{GF}_{254}$ plates with ultraviolet (UV) light detection.

\subsubsection{Synthesis of Methyl 3-((Diethoxyphosphoryl)methyl)benzoate (11)}

A solution of methyl 3-methylbenzoate $(47 \mathrm{~g}, 0.31 \mathrm{~mol})$ in $\mathrm{CCl}_{4}(200 \mathrm{~mL})$ was heated to reflux followed by addition of AIBN (2.6 g) in one portion. After that, NBS (67 g, 0.38 mol) was added carefully to the mixture during $2 \mathrm{~h}$, and then the reaction was refluxed for an additional $5 \mathrm{~h}$. After cooling to r.t. the mixture was filtered and evaporated under vacuum to give methyl 3-(bromomethyl)benzoate (10,67 g, Yield: 94\%) as a yellowish oil. The obtained oil was then dissolved in triethyl phosphate $(130 \mathrm{~g}, 0.71 \mathrm{~mol})$, heated to $160{ }^{\circ} \mathrm{C}$ and kept at this temperature for an additional $10 \mathrm{~h}$. The mixture was concentrated on a rotary evaporator and then purified by flash chromatography (PE:EA = 5:1 PE:EA = 1:3) to give 11 as a yellow oil, which was used without any further purification.

\subsubsection{Synthesis of (E)-3-(4-Methoxystyryl)benzoic Acid (12)}

To an ice-cooled solution of compound 11 (5 g, about $17.5 \mathrm{mmol})$ in THF (30 mL) was added a mixture of $t$-BuOK $(3.9 \mathrm{~g}, 34.8 \mathrm{mmol})$ and THF $(40 \mathrm{~mL})$ during $30 \mathrm{~min}$. After stirring for additional $30 \mathrm{~min}$, a solution of 4-methoxybenzaldehyde $(17.5 \mathrm{mmol})$ in THF $(20 \mathrm{~mL})$ was added and then the reaction mixture was warmed to room temperature, and stirred for another $8 \mathrm{~h}$ before quenching with $2 \mathrm{~N} \mathrm{HCl}$. The mixture was then evaporated to remove the THF and precipitation occurred meanwhile. The precipitate was then filtered and dried to give $\mathbf{1 2}$ as a yellow solid without any additional purification. Yield: $4.8 \mathrm{~g}(46 \%) ;{ }^{1} \mathrm{H}-\mathrm{NMR}$ (DMSO- $\left.d_{6}\right) \delta: 12.93$ (brs, $\left.1 \mathrm{H}\right), 8.12(\mathrm{~s}, 1 \mathrm{H}), 7.81$ $(\mathrm{d}, J=7.6 \mathrm{~Hz}, 2 \mathrm{H}), 7.58(\mathrm{~d}, J=8.6 \mathrm{~Hz}, 2 \mathrm{H}), 7.49(\mathrm{t}, J=7.8 \mathrm{~Hz}, 1 \mathrm{H}), 7.28(\mathrm{~d}, J=16.5 \mathrm{~Hz}, 1 \mathrm{H}), 7.18$ $(\mathrm{d}, J=16.5 \mathrm{~Hz}, 1 \mathrm{H}), 6.96(\mathrm{~d}, J=8.6 \mathrm{~Hz}, 2 \mathrm{H}), 3.78(\mathrm{~s}, 3 \mathrm{H})$.

\subsubsection{Synthesis of (E)-3-(4-Hydroxystyryl)benzoic Acid (13)}

Anhydrous aluminium trichloride $(30 \mathrm{~g})$ was added to triethylamine $(200 \mathrm{~mL})$ in portions during $30 \mathrm{~min}$ and then heated to $60{ }^{\circ} \mathrm{C}$ for $3 \mathrm{~h}$ before adding compound $12(16.5 \mathrm{~g}, 65.0 \mathrm{mmol})$ in one portion. The resultant mixture was then heated to $80^{\circ} \mathrm{C}$ and kept for another $16 \mathrm{~h}$. After evaporating most of the triethylamine, the reaction was quenched by addition of iced hydrochloric acid. The water phase was extracted by ethyl acetate $(80 \mathrm{~mL} \times 3)$, dried over anhydrous $\mathrm{Na}_{2} \mathrm{SO}_{4}$, filtered and then evaporated to give crude 13, which was then recrystallized from ethyl acetate to give $\mathbf{1 3}$ as a yellowish solid. Yield: $7.8 \mathrm{~g}(48 \%) ;{ }^{1} \mathrm{H}-\mathrm{NMR}\left(\mathrm{DMSO}-\mathrm{d}_{6}\right) \delta: 12.98$ (brs, $\left.1 \mathrm{H}\right), 9.63(\mathrm{~s}, 1 \mathrm{H}), 8.09(\mathrm{~s}, 1 \mathrm{H}), 7.78 \sim 7.81(\mathrm{~m}$, 2H), $7.48 \sim 7.49(\mathrm{~m}, 3 \mathrm{H}), 7.13 \sim 7.15(\mathrm{~m}, 2 \mathrm{H}), 6.78(\mathrm{~d}, J=8.7 \mathrm{~Hz}, 2 \mathrm{H})$.

\subsubsection{Synthesis of Methyl (E)-3-(4-Hydroxystyryl)benzoate (14)}

Anhydrous $\mathrm{K}_{2} \mathrm{CO}_{3}(0.58 \mathrm{~g}, 4.2 \mathrm{mmol})$ was added to a solution of $\mathbf{1 3}(1.68 \mathrm{~g}, 7 \mathrm{mmol})$ in acetone $(15 \mathrm{~mL})$, and the mixture was then stirred for $2 \mathrm{~h}$ at room temperature before adding MeI (1.07 $\mathrm{g}$, $4.2 \mathrm{mmol}$ ) in one portion. The reaction was then stirred for an additional $16 \mathrm{~h}$. After that, the mixture was filtered, evaporated and purified by column chromatography (PE:EA = 3:1) to give 14 as a yellowish solid. Yield: $0.29 \mathrm{~g}(51 \%) ;{ }^{1} \mathrm{H}-\mathrm{NMR}\left(\mathrm{DMSO}-\mathrm{d}_{6}\right) \delta: 9.64(\mathrm{~s}, 1 \mathrm{H}), 8.10(\mathrm{~s}, 1 \mathrm{H}), 7.79 \sim 7.85(\mathrm{~m}, 2 \mathrm{H})$, $7.46 \sim 7.50(\mathrm{~m}, 3 \mathrm{H}), 7.25(\mathrm{~d}, J=16.5 \mathrm{~Hz}, 1 \mathrm{H}), 7.12(\mathrm{~d}, J=16.5 \mathrm{~Hz}, 1 \mathrm{H}), 6.78(\mathrm{~d}, J=8.5 \mathrm{~Hz}, 2 \mathrm{H}), 3.88(\mathrm{~s}$, $3 \mathrm{H}) ;{ }^{13}$ C-NMR (DMSO-d 6 ) $\delta:$ 166.2, 157.6, 138.2, 130.3, 130.1, 129.7, 129.1, 128.1 (2C), 127.7, 127.4, 126.6, $123.9,115.5(2 \mathrm{C}), 52.1$.

\subsubsection{Synthesis of (3-Phenylisoxazol-4-yl)methanol (15b)}

On an ice bath, to a solution of $15 a(5 \mathrm{mmol})$ in anhydrous THF $(20 \mathrm{~mL})$ was added $\mathrm{LiAlH}_{4}$ $(5 \mathrm{mmol})$ in portions during $30 \mathrm{~min}$. After that, the mixture was stirred for $2 \mathrm{~h}$ and quenched by $1 \mathrm{~mL}$ 
$\mathrm{H}_{2} \mathrm{O}$ added dropwise. After adding anhydrous $\mathrm{Na}_{2} \mathrm{SO}_{4}(5 \mathrm{~g})$, the reaction was filtered and evaporated to give $\mathbf{1 5 b}$, which was used in the next step without any purification. Intermediates $\mathbf{1 6 b} \mathbf{3 0 b}$ were synthesized according to methods described above for the synthesis of $\mathbf{1 5 b}$.

\subsubsection{Synthesis of 4-(Chloromethyl)-3-phenylisoxazole (15c)}

To a solution of $\mathbf{1 5 b}$ ( $3 \mathrm{mmol}), \mathrm{DCM}(20 \mathrm{~mL})$ and DMF (1 2 drops), $\mathrm{SOCl}_{2}$ (10 mmol) was added and heated to $45^{\circ} \mathrm{C}$. After keeping at this temperature for $8 \mathrm{~h}$, the solution was evaporated to give 15c as yellow oil, which was used in the next step without any purification. Intermediates 16c 30c were synthesized according to the above method for the synthesis of $15 \mathrm{c}$ and purified by column chromatography (PE:EA = 5:1 10:1) if necessary.

\subsubsection{Synthesis of (E)-3-(4-((3-Phenylisoxazol-4-yl)methoxy)styryl)benzoic Acid (15)}

A mixture of $14(1 \mathrm{mmol}), 15 \mathrm{c}(1 \mathrm{mmol})$ and $\mathrm{Cs}_{2} \mathrm{CO}_{3}(2 \mathrm{mmol})$ in DMSO $(5 \mathrm{~mL})$ was heated to $85^{\circ} \mathrm{C}$ and kept at this temperature for $8 \mathrm{~h}$, then the reaction mixture was cooled to $60{ }^{\circ} \mathrm{C}$ followed by the addition of $20 \% \mathrm{KOH}$ solution $\left(2 \mathrm{~mL}\right.$ ). After stirring at $60{ }^{\circ} \mathrm{C}$ for $4 \mathrm{~h}$, the reaction mixture was cooled, acidified by $1 \mathrm{~N}$ hydrochloric acid diluted with water to give a mass of precipitate of the crude product, which was then recrystallized from methanol to give the purified 15. Yellow solid; Yield: 63\%;

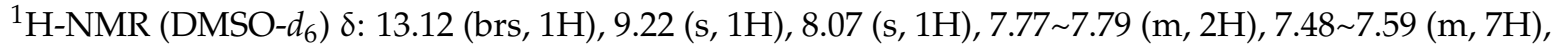
$7.27(\mathrm{t}, J=7.6 \mathrm{~Hz}, 1 \mathrm{H}), 7.18(\mathrm{~d}, J=16.5 \mathrm{~Hz}, 1 \mathrm{H}), 7.13(\mathrm{~d}, J=16.5 \mathrm{~Hz}, 1 \mathrm{H}), 7.04(\mathrm{~d}, J=8.8 \mathrm{~Hz}, 2 \mathrm{H}), 5.13$ $(\mathrm{s}, 2 \mathrm{H}) ;{ }^{13} \mathrm{C}-\mathrm{NMR}\left(\mathrm{DMSO}-d_{6}\right) \delta: 169.2,161.3,159.2,157.7,136.7,131.0,130.6,129.6$ (2C), 129.4, 128.7, 128.6, 128.4 (2C), 128.3 (2C), 128.0, 127.8, 127.4, 127.3, 115.6 (2C), 114.6, 59.1; HRMS (ESI) calcd for $\mathrm{C}_{25} \mathrm{H}_{18} \mathrm{NO}_{4}[\mathrm{M}-\mathrm{H}]^{-}$396.1236, found 396.1265 (see Supplementary Materials). Compounds 16 30 were synthesized according to the above method for the synthesis of $\mathbf{1 5}$.

(E)-3-(4-((5-Phenylisoxazol-4-yl)methoxy)styryl)benzoic acid (16): Yellow solid; Yield: 47\%; ${ }^{1} \mathrm{H}-\mathrm{NMR}$ $\left(\mathrm{DMSO}-d_{6}\right) \delta: 13.15$ (brs, 1H), $9.22(\mathrm{~s}, 1 \mathrm{H}), 8.13(\mathrm{~s}, 1 \mathrm{H}), 7.77 \sim 7.80(\mathrm{~m}, 4 \mathrm{H}), 7.60(\mathrm{~d}, J=8.7 \mathrm{~Hz}, 2 \mathrm{H})$, $7.52 \sim 7.54(\mathrm{~m}, 4 \mathrm{H}), 7.31(\mathrm{~d}, J=16.5 \mathrm{~Hz}, 1 \mathrm{H}), 7.22(\mathrm{~d}, J=16.5 \mathrm{~Hz}, 1 \mathrm{H}), 7.07(\mathrm{~d}, J=8.7 \mathrm{~Hz}, 2 \mathrm{H}), 5.14(\mathrm{~s}$, $2 \mathrm{H}) ;{ }^{13} \mathrm{C}-\mathrm{NMR}\left(\mathrm{DMSO}-d_{6}\right) \delta: 169.5,161.3,159.1,158.1,138.4,131.0,130.6,130.5,129.7,129.6,129.5$ (2C), 129.4, 128.6 (2C), 128.4 (2C), 128.2, 127.8, 127.3, 125.9, 115.6 (2C), 114.6, 59.1; HRMS (ESI) calcd for $\mathrm{C}_{25} \mathrm{H}_{18} \mathrm{NO}_{4}[\mathrm{M}-\mathrm{H}]^{-}$396.1236, found 396.1212.

(E)-3-(4-((5-Methyl-3-phenylisoxazol-4-yl)methoxy)styryl)benzoic acid (17): Yellow solid; Yield: 42\%;

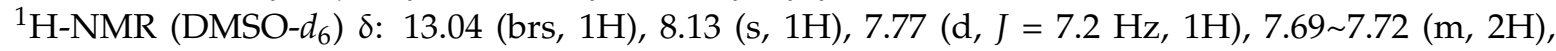
$7.62(\mathrm{~d}, J=7.8 \mathrm{~Hz}, 1 \mathrm{H}), 7.58(\mathrm{~d}, J=8.6 \mathrm{~Hz}, 1 \mathrm{H}), 7.49 \sim 7.52(\mathrm{~m}, 3 \mathrm{H}), 7.36(\mathrm{t}, J=7.7 \mathrm{~Hz}, 1 \mathrm{H}), 7.23(\mathrm{~d}$, $J=16.5 \mathrm{~Hz}, 1 \mathrm{H}), 7.12(\mathrm{~d}, J=16.5 \mathrm{~Hz}, 1 \mathrm{H}), 7.02(\mathrm{~s}, 1 \mathrm{H}), 7.10(\mathrm{~d}, J=8.6 \mathrm{~Hz}, 2 \mathrm{H}), 5.00(\mathrm{~s}, 2 \mathrm{H}), 2.53(\mathrm{~s}, 3 \mathrm{H})$; ${ }^{13}$ C-NMR (DMSO-d $)_{6}$ ) $:$ 170.4, 168.3, 162.6, 158.1, 137.3, 130.9, 130.4, 129.5 (2C), 129.1, 129.0, 128.7, 128.6, 128.4, 128.3 (2C), 128.2 (2C), 127.4, 126.9, 115.7 (2C), 109.9, 59.5, 11.3; HRMS (ESI) calcd for $\mathrm{C}_{26} \mathrm{H}_{20} \mathrm{NO}_{4}$ $[\mathrm{M}-\mathrm{H}]^{-}$410.1392, found 410.1388 .

(E)-3-(4-((5-Phenylisoxazol-3-yl)methoxy)styryl)benzoic acid (18): Yellow solid; Yield: $42 \% ;{ }^{1} \mathrm{H}-\mathrm{NMR}$ $\left(\mathrm{DMSO}-d_{6}\right) \delta: 13.15$ (brs, $\left.1 \mathrm{H}\right), 8.12(\mathrm{~s}, 1 \mathrm{H}), 7.90\left(\mathrm{dd}, J_{1}=8.0 \mathrm{~Hz}, J_{2}=1.8 \mathrm{~Hz}, 2 \mathrm{H}\right), 7.80(\mathrm{t}, J=7.5 \mathrm{~Hz}$, $2 \mathrm{H}), 7.62(\mathrm{~d}, J=8.8 \mathrm{~Hz}, 2 \mathrm{H}), 7.52 \sim 7.58(\mathrm{~m}, 3 \mathrm{H}), 7.47(\mathrm{t}, J=7.7 \mathrm{~Hz}, 1 \mathrm{H}), 7.29(\mathrm{~d}, J=16.4 \mathrm{~Hz}, 1 \mathrm{H}), 7.22(\mathrm{~d}$, $J=16.4 \mathrm{~Hz}, 1 \mathrm{H}), 7.20(\mathrm{~s}, 1 \mathrm{H}), 7.10(\mathrm{~d}, J=8.8 \mathrm{~Hz}, 2 \mathrm{H}), 5.29(\mathrm{~s}, 2 \mathrm{H}) ;{ }^{13} \mathrm{C}-\mathrm{NMR}\left(\mathrm{DMSO}-d_{6}\right) \delta: 170.0,168.2$, 161.8, 158.1, 138.0, 131.1, 130.8, 130.3, 129.8 (2C), 129.3, 129.2, 128.5 (2C), 128.4, 127.4, 127.1, 126.3, 126.1 (2C), 115.6 (2C), 100.5, 61.8; HRMS (ESI) calcd for $\mathrm{C}_{25} \mathrm{H}_{18} \mathrm{NO}_{4}[\mathrm{M}-\mathrm{H}]^{-}$396.1236, found 396.1219.

(E)-3-(4-((5-(2-Chlorophenyl)isoxazol-3-yl)methoxy)styryl)benzoic acid (19): Yellow solid; Yield: 51\%; ${ }^{1} \mathrm{H}-\mathrm{NMR}\left(\mathrm{DMSO}_{6}\right)$ 8: $13.02(\mathrm{~s}, 1 \mathrm{H}), 8.12(\mathrm{~s}, 1 \mathrm{H}), 7.99(\mathrm{~d}, J=8.4 \mathrm{~Hz}, 1 \mathrm{H}), 7.97(\mathrm{~d}, J=5.5 \mathrm{~Hz}, 1 \mathrm{H})$, $7.78 \sim 7.85(\mathrm{~m}, 3 \mathrm{H}), 7.62(\mathrm{~d}, J=8.4 \mathrm{~Hz}, 2 \mathrm{H}), 7.46 \sim 7.51(\mathrm{~m}, 2 \mathrm{H}), 7.40(\mathrm{t}, J=8.7 \mathrm{~Hz}, 2 \mathrm{H}), 7.30(\mathrm{~d}, J=16.4 \mathrm{~Hz}$, $1 \mathrm{H}), 7.22(\mathrm{~d}, J=16.4 \mathrm{~Hz}, 1 \mathrm{H}), 7.18(\mathrm{~s}, 1 \mathrm{H}), 7.09(\mathrm{~d}, J=8.4 \mathrm{~Hz}, 2 \mathrm{H}), 5.28(\mathrm{~s}, 2 \mathrm{H}) ;{ }^{13} \mathrm{C}-\mathrm{NMR}\left(\mathrm{DMSO}-d_{6}\right)$ $\delta: 168.6,167.3,161.3,157.6,137.7,131.2,130.2,128.9,128.2,128.1,128.1,128.0$ (2C), 127.9, 126.9, 124.1, 
125.6, 116.5, 116.3, 115.5, 115.1 (2C), 99.9, 61.3; HRMS (ESI) calcd for $\mathrm{C}_{25} \mathrm{H}_{17} \mathrm{ClNO}_{4}[\mathrm{M}-\mathrm{H}]^{-}$430.0846, found 430.0831 .

(E)-3-(4-((5-(2-Methoxyphenyl)isoxazol-3-yl)methoxy)styryl)benzoic acid (20): Yellow solid; Yield: 47\%; ${ }^{1} \mathrm{H}-\mathrm{NMR}$ (DMSO-d $\left.d_{6}\right) \delta: 13.05$ (brs, 1H), $8.13(\mathrm{~s}, 1 \mathrm{H}), 7.79 \sim 7.83(\mathrm{~m}, 2 \mathrm{H}), 7.62(\mathrm{~d}, J=8.8 \mathrm{~Hz}, 2 \mathrm{H}), 7.46 \sim 7.52$ $(\mathrm{m}, 3 \mathrm{H}), 7.26(\mathrm{~d}, J=16.4 \mathrm{~Hz}, 1 \mathrm{H}), 7.20(\mathrm{~d}, J=16.4 \mathrm{~Hz}, 1 \mathrm{H}), 7.10 \sim 7.14(\mathrm{~m}, 2 \mathrm{H}), 6.99(\mathrm{~s}, 1 \mathrm{H}), 6.79(\mathrm{~d}$, $J=8.8 \mathrm{~Hz}, 2 \mathrm{H}), 5.29(\mathrm{~s}, 2 \mathrm{H}), 3.96(\mathrm{~s}, 3 \mathrm{H}) ;{ }^{13} \mathrm{C}-\mathrm{NMR}\left(\mathrm{DMSO}-d_{6}\right) \delta: 167.8,166.2,161.5,158.2,138.4,138.2$, $131.7,130.7,130.5,130.0,129.4,129.4,128.6$ (2C), 128.2, 127.4, 127.2, 126.1, 124.6, 121.3, 115.6 (2C), 103.6, 61.8, 56.3; HRMS (ESI) calcd for $\mathrm{C}_{26} \mathrm{H}_{20} \mathrm{NO}_{5}[\mathrm{M}-\mathrm{H}]^{-} 426.1341$, found 426.1376 .

(E)-3-(4-((5-(3-Chlorophenyl)isoxazol-3-yl)methoxy)styryl)benzoic acid (21): Yellow solid; Yield: 40\%; ${ }^{1} \mathrm{H}-\mathrm{NMR}$ (DMSO- $\left.d_{6}\right) \delta: 13.12(\mathrm{brs}, 1 \mathrm{H}), 8.13(\mathrm{~s}, 1 \mathrm{H}), 8.01(\mathrm{~s}, 1 \mathrm{H}), 7.78 \sim 7.82(\mathrm{~m}, 2 \mathrm{H}), 7.62(\mathrm{~d}, J=8.6 \mathrm{~Hz}$, $2 \mathrm{H}), 7.58 \sim 7.59(\mathrm{~m}, 2 \mathrm{H}), 7.46 \sim 7.50(\mathrm{~m}, 2 \mathrm{H}), 7.33(\mathrm{~s}, 1 \mathrm{H}), 7.30(\mathrm{~d}, J=16.4 \mathrm{~Hz}, 1 \mathrm{H}), 7.22(\mathrm{~d}, J=16.4 \mathrm{~Hz}, 1 \mathrm{H})$, $7.10(\mathrm{~d}, J=8.6 \mathrm{~Hz}, 2 \mathrm{H}), 5.30(\mathrm{~s}, 2 \mathrm{H}){ }^{13}{ }^{13} \mathrm{C}-\mathrm{NMR}$ (DMSO- $\left.d_{6}\right) \delta: 168.5,167.9,161.9,158.1,138.2,134.5,131.7$, 130.8, 130.6, 130.0, 129.4, 129.0, 128.5, 127.4, 126.2 (2C), 125.8, 124.7, 124.6, 115.6 (2C), 101.7; HRMS (ESI) calcd for $\mathrm{C}_{25} \mathrm{H}_{17} \mathrm{ClNO}_{4}[\mathrm{M}-\mathrm{H}]^{-} 430.0846$, found 430.0857 .

(E)-3-(4-((5-(3-Fluorophenyl)isoxazol-3-yl)methoxy)styryl)benzoic acid (22): Yellow solid; Yield: 48\%; ${ }^{1} \mathrm{H}-\mathrm{NMR}$ (DMSO- $\left.d_{6}\right) \delta: 13.05$ (brs, $\left.1 \mathrm{H}\right), 8.13(\mathrm{~s}, 1 \mathrm{H}), 7.76 \sim 7.84(\mathrm{~m}, 4 \mathrm{H}), 7.58 \sim 7.64(\mathrm{~m}, 3 \mathrm{H}), 7.49(\mathrm{t}$, $J=7.7 \mathrm{~Hz}, 1 \mathrm{H}), 7.29 \sim 7.40(\mathrm{~m}, 3 \mathrm{H}), 7.22(\mathrm{~d}, J=16.4 \mathrm{~Hz}, 1 \mathrm{H}), 7.10(\mathrm{~d}, J=8.7 \mathrm{~Hz}, 2 \mathrm{H}), 5.30(\mathrm{~s}, 2 \mathrm{H})$; ${ }^{13}$ C-NMR (DMSO- $\left.d_{6}\right) \delta: 168.7,167.7,162.9(\mathrm{~d}, J=145.6 \mathrm{~Hz}), 161.9,158.1,138.2,132.1,132.0,131.7$, 130.7, 129.4, 129.1, 129.0, $128.5(2 \mathrm{C}), 128.4,127.4,126.2,122.3,118.2(\mathrm{~d}, J=21.2 \mathrm{~Hz}), 115.6(2 \mathrm{C}), 113.0$ (d, $J=23.7 \mathrm{~Hz}$ ), 101.6, 61.7; HRMS (ESI) calcd for $\mathrm{C}_{25} \mathrm{H}_{17} \mathrm{FNO}_{4}[\mathrm{M}-\mathrm{H}]^{-} 414.1142$, found 414.1133 .

(E)-3-(4-((5-(3-Bromophenyl)isoxazol-3-yl)methoxy)styryl)benzoic acid (23): Yellow solid; Yield: 51\%; ${ }^{1} \mathrm{H}-\mathrm{NMR}\left(\mathrm{DMSO}-d_{6}\right) \delta: 13.13(\mathrm{brs}, 1 \mathrm{H}), 8.14(\mathrm{~s}, 1 \mathrm{H}), 8.12(\mathrm{~s}, 1 \mathrm{H}), 7.89 \sim 7.93(\mathrm{~m}, 1 \mathrm{H}), 7.79(\mathrm{~d}, J=7.6 \mathrm{~Hz}$, $1 \mathrm{H}), 7.71 \sim 7.73(\mathrm{~m}, 1 \mathrm{H}), 7.61(\mathrm{~d}, J=8.7 \mathrm{~Hz}, 2 \mathrm{H}), 7.49 \sim 7.58(\mathrm{~m}, 2 \mathrm{H}), 7.43(\mathrm{t}, J=7.6 \mathrm{~Hz}, 1 \mathrm{H}), 7.27(\mathrm{~d}$, $J=16.5 \mathrm{~Hz}, 1 \mathrm{H}), 7.20(\mathrm{~d}, J=16.5 \mathrm{~Hz}, 1 \mathrm{H}), 7.19(\mathrm{~s}, 1 \mathrm{H}), 7.09(\mathrm{~d}, J=8.7 \mathrm{~Hz}, 2 \mathrm{H}), 5.29(\mathrm{~s}, 2 \mathrm{H}) ;{ }^{13} \mathrm{C}-\mathrm{NMR}$ (DMSO- $d_{6}$ ) $\delta: 170.0,168.4,161.8,158.0,137.8,133.7,131.9,131.0,130.9,129.8,129.1,128.9,128.7,128.5$ (2C), 127.4, 126.6, 126.1, 125.0, 123.0, 115.6 (2C), 100.5, 61.7; HRMS (ESI) calcd for $\mathrm{C}_{25} \mathrm{H}_{17} \mathrm{BrNO}_{4}$ $[\mathrm{M}-\mathrm{H}]^{-}$474.0341, found 474.0371.

(E)-3-(4-((5-(m-Tolyl)isoxazol-3-yl)methoxy)styryl)benzoic acid (24): Yellow solid; Yield: 44\%; ${ }^{1} \mathrm{H}-\mathrm{NMR}$ (DMSO- $\left.d_{6}\right) \delta: 13.05($ brs, $1 \mathrm{H}), 8.12(\mathrm{~s}, 1 \mathrm{H}), 7.96(\mathrm{~s}, 1 \mathrm{H}), 7.80(\mathrm{t}, J=7.0 \mathrm{~Hz}, 2 \mathrm{H}), 7.61 \sim 7.73(\mathrm{~m}, 4 \mathrm{H})$, $7.41 \sim 7.49(\mathrm{~m}, 2 \mathrm{H}), 7.33(\mathrm{~d}, J=16.5 \mathrm{~Hz}, 1 \mathrm{H}), 7.25(\mathrm{~d}, J=16.5 \mathrm{~Hz}, 1 \mathrm{H}), 7.41(\mathrm{~s}, 1 \mathrm{H}), 7.10(\mathrm{~d}, J=8.8 \mathrm{~Hz}, 2 \mathrm{H})$, $5.28(\mathrm{~s}, 2 \mathrm{H}), 2.39$ (s, 3H); ${ }^{13} \mathrm{C}-\mathrm{NMR}$ (DMSO- $\left.d_{6}\right) \delta: 170.2,168.1,161.7,158.1,139.2,138.0,131.7,130.7$, 130.3, 129.7, 129.3, 129.2, 128.5 (2C), 128.4, 127.4, 127.0, 126.5, 126.3, 123.3, 115.6 (2C), 100.4, 61.8, 21.3; HRMS (ESI) calcd for $\mathrm{C}_{26} \mathrm{H}_{20} \mathrm{NO}_{4}[\mathrm{M}-\mathrm{H}]^{-} 410.1392$, found 410.1388 .

(E)-3-(4-((5-(3-Nitrophenyl)isoxazol-3-yl)methoxy)styryl)benzoic acid (25): Yellow solid; Yield: 38\%; ${ }^{1} \mathrm{H}-\mathrm{NMR}$ (DMSO- $\left.d_{6}\right) \delta: 13.17(\mathrm{brs}, 1 \mathrm{H}), 8.35(\mathrm{~s}, 1 \mathrm{H}), 8.13(\mathrm{~s}, 1 \mathrm{H}), 7.78 \sim 7.83(\mathrm{~m}, 3 \mathrm{H}), 7.63(\mathrm{~d}, J=8.8 \mathrm{~Hz}$, $2 \mathrm{H}), 7.46 \sim 7.49(\mathrm{~m}, 4 \mathrm{H}), 7.28(\mathrm{~d}, J=16.5 \mathrm{~Hz}, 1 \mathrm{H}), 7.22(\mathrm{~d}, J=16.5 \mathrm{~Hz}, 1 \mathrm{H}), 7.11(\mathrm{~d}, J=8.8 \mathrm{~Hz}, 2 \mathrm{H}), 5.33$ $(\mathrm{s}, 2 \mathrm{H}) ;{ }^{13} \mathrm{C}-\mathrm{NMR}$ (DMSO- $d_{6}$ ) $\delta: 167.7,162.2,158.0,148.9,138.5,138.2,131.7,130.7,130.5,130.0,129.4$, 128.6 (2C), 128.4, 127.4, 127.2, 126.2, 125.4, 124.6, 120.7, 115.6 (2C), 102.5, 61.7; HRMS (ESI) calcd for $\mathrm{C}_{25} \mathrm{H}_{17} \mathrm{~N}_{2} \mathrm{O}_{6}[\mathrm{M}-\mathrm{H}]^{-}$441.1087, found 441.1072 .

(E)-3-(4-((5-(p-Tolyl)isoxazol-3-yl)methoxy)styryl)benzoic acid (26): Yellow solid; Yield: $55 \%$; ${ }^{1} \mathrm{H}-\mathrm{NMR}$ (DMSO- $d_{6}$ ) $\delta: 12.98$ (brs, $\left.1 \mathrm{H}\right), 8.13(\mathrm{~s}, 1 \mathrm{H}), 7.82 \sim 7.88(\mathrm{~m}, 2 \mathrm{H}), 7.79(\mathrm{~d}, J=8.1 \mathrm{~Hz}, 1 \mathrm{H}), 7.62(\mathrm{~d}, J=8.6 \mathrm{~Hz}$, $2 \mathrm{H}), 7.49 \sim 7.54(\mathrm{~m}, 1 \mathrm{H}), 7.35(\mathrm{~d}, J=8.1 \mathrm{~Hz}, 2 \mathrm{H}), 7.47(\mathrm{t}, J=7.7 \mathrm{~Hz}, 1 \mathrm{H}), 7.28(\mathrm{~d}, J=16.5 \mathrm{~Hz}, 1 \mathrm{H}), 7.23(\mathrm{~d}$, $J=16.5 \mathrm{~Hz}, 1 \mathrm{H}), 7.10(\mathrm{~d}, J=8.6 \mathrm{~Hz}, 2 \mathrm{H}), 7.09(\mathrm{~s}, 1 \mathrm{H}), 5.27(\mathrm{~s}, 2 \mathrm{H}), 2.37(\mathrm{~s}, 3 \mathrm{H}) ; 170.2,166.7,161.7,158.2$, 141.0, 138.4 131.0, 130.6, 130.3 (2C), 129.7, 129.6, 128.6 (2C), 127.3, 126.1 (2C), 125.9, 124.4, 115.6 (2C), 99.9, 61.8, 21.5; HRMS (ESI) calcd for $\mathrm{C}_{26} \mathrm{H}_{20} \mathrm{NO}_{4}[\mathrm{M}-\mathrm{H}]^{-} 410.1392$, found 410.1373.

(E)-3-(4-((5-(4-Methoxyphenyl)isoxazol-3-yl)methoxy)styryl)benzoic acid (27): Yellow solid; Yield: 52\%; ${ }^{1} \mathrm{H}-\mathrm{NMR}\left(\mathrm{DMSO}-d_{6}\right)$ ): 13.04 (brs, $\left.1 \mathrm{H}\right), 8.12(\mathrm{~s}, 1 \mathrm{H}), 7.77 \sim 7.86(\mathrm{~m}, 5 \mathrm{H}), 7.62(\mathrm{~d}, J=8.4 \mathrm{~Hz}, 2 \mathrm{H}), 7.46 \sim 7.54$ 
$(\mathrm{m}, 2 \mathrm{H}), 7.30(\mathrm{~d}, J=16.5 \mathrm{~Hz}, 1 \mathrm{H}), 7.22(\mathrm{~d}, J=16.5 \mathrm{~Hz}, 1 \mathrm{H}), 7.09(\mathrm{~d}, J=8.4 \mathrm{~Hz}, 2 \mathrm{H}), 7.04(\mathrm{~s}, 1 \mathrm{H}), 5.26$

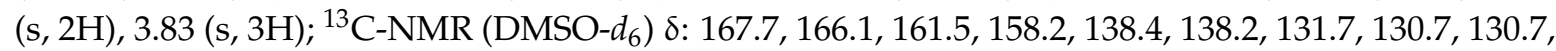
130.0, 129.4, 128.6 (2C), 127.7, 127.5, 127.4, 127.2, 126.1, 124.6, 120.0, 115.2 (2C), 100.0, 61.8, 55.7; HRMS (ESI) calcd for $\mathrm{C}_{26} \mathrm{H}_{20} \mathrm{NO}_{5}[\mathrm{M}-\mathrm{H}]^{-} 426.1341$, found 426.1365 .

(E)-3-(4-((5-(4-Fluorophenyl)isoxazol-3-yl)methoxy)styryl)benzoic acid (28): Yellow solid; Yield: 37\%; ${ }^{1} \mathrm{H}-\mathrm{NMR}$ (DMSO- $\left.d_{6}\right) \delta: 13.10(\mathrm{brs}, 1 \mathrm{H}), 8.13(\mathrm{~s}, 1 \mathrm{H}), 7.83 \sim 7.95(\mathrm{~m}, 5 \mathrm{H}), 7.64(\mathrm{~d}, J=8.5 \mathrm{~Hz}, 2 \mathrm{H})$, $7.48 \sim 7.55(\mathrm{~m}, 2 \mathrm{H}), 7.31(\mathrm{~d}, J=16.5 \mathrm{~Hz}, 1 \mathrm{H}), 7.24(\mathrm{~d}, J=16.5 \mathrm{~Hz}, 1 \mathrm{H}), 7.21(\mathrm{~s}, 1 \mathrm{H}), 7.11(\mathrm{~d}, J=8.4 \mathrm{~Hz}$, 2H), 5.33 (s, 2H); ${ }^{13} \mathrm{C}-\mathrm{NMR}$ (DMSO- $\left.d_{6}\right) \delta: 168.1,166.7,161.5,158.8(\mathrm{~d}, J=154.0 \mathrm{~Hz}, 2 \mathrm{C}), 158.1,139.4$, 132.5, 132.4 (2C), 130.9,129.9, 128.7 (2C), 128.5, 128.2, 127.9, 127.3, $126.2(\mathrm{~d}, J=26.5 \mathrm{~Hz}, 2 \mathrm{C}), 124.6,115.5$ (2C), 104.8, 61.8; HRMS (ESI) calcd for $\mathrm{C}_{25} \mathrm{H}_{17} \mathrm{FNO}_{4}[\mathrm{M}-\mathrm{H}]^{-} 414.1142$, found 414.1159.

(E)-3-(4-((5-(3,4-Dichlorophenyl)isoxazol-3-yl)methoxy)styryl)benzoic acid (29): Yellow solid; Yield: 52\%; ${ }^{1} \mathrm{H}-\mathrm{NMR}$ (DMSO- $d_{6}$ ) $\delta: 13.03$ (brs, 1H), $8.22(\mathrm{~s}, 1 \mathrm{H}), 8.12(\mathrm{~s}, 1 \mathrm{H}), 7.80 \sim 7.83(\mathrm{~m}, 3 \mathrm{H}), 7.62(\mathrm{~d}, J=8.7 \mathrm{~Hz}$, $2 \mathrm{H}), 7.45 \sim 7.52(\mathrm{~m}, 2 \mathrm{H}), 7.37(\mathrm{~s}, 1 \mathrm{H}), 7.30(\mathrm{~d}, J=16.4 \mathrm{~Hz}, 1 \mathrm{H}), 7.23(\mathrm{~d}, J=16.4 \mathrm{~Hz}, 1 \mathrm{H}), 7.09(\mathrm{~d}, J=8.7 \mathrm{~Hz}$, 2H), 5.30 (s, 2H); ${ }^{13} \mathrm{C}-\mathrm{NMR}$ (DMSO- $\left.d_{6}\right) \delta: 167.3,167.1,161.5,157.5,137.7,133.1,132.2,131.6,131.3$, 130.5, 130.3, 130.2, 130.1, 129.1, 128.9, 128.1, 128.0 (2C), 127.5, 127.0, 126.9, 125.7, 115.5, 115.1 (2C), 101.6, 61.2; HRMS (ESI) calcd for $\mathrm{C}_{25} \mathrm{H}_{16} \mathrm{Cl}_{2} \mathrm{NO}_{4}[\mathrm{M}-\mathrm{H}]^{-}$464.0456, found 464.0438.

(E)-3-(4-((5-(3,4-Difluorophenyl)isoxazol-3-yl)methoxy)styryl)benzoic acid (30): Yellow solid; Yield: 45\%; ${ }^{1} \mathrm{H}-\mathrm{NMR}$ (DMSO- $d_{6}$ ) $\delta: 13.09$ (brs, $\left.1 \mathrm{H}\right), 8.10(\mathrm{~s}, 1 \mathrm{H}), 8.03 \sim 8.08(\mathrm{~m}, 1 \mathrm{H}), 7.72 \sim 7.80(\mathrm{~m}, 3 \mathrm{H}), 7.57 \sim 7.67(\mathrm{~m}$, $3 \mathrm{H}), 7.43(\mathrm{t}, J=7.7 \mathrm{~Hz}, 1 \mathrm{H}), 7.17 \sim 7.29(\mathrm{~m}, 3 \mathrm{H}), 7.08(\mathrm{~d}, J=8.7 \mathrm{~Hz}, 1 \mathrm{H}), 6.96(\mathrm{~d}, J=8.5 \mathrm{~Hz}, 1 \mathrm{H}), 5.29$ $(\mathrm{s}, 2 \mathrm{H}) ;{ }^{13} \mathrm{C}-\mathrm{NMR}\left(\mathrm{DMSO}-d_{6}\right) \delta: 167.3,167.2,159.1,157.5,137.9,137.7,130.7$ (d, J = 97.3 Hz), 130.6 (d, $J=97.0 \mathrm{~Hz}), 130.0,129.5,128.9,128.1,128.0,127.7,127.6,126.9,126.7,125.6,124.1,115.5,115.1,100.9$, 61.2; HRMS (ESI) calcd for $\mathrm{C}_{25} \mathrm{H}_{16} \mathrm{~F}_{2} \mathrm{NO}_{4}[\mathrm{M}-\mathrm{H}]^{-}$432.1047, found 432.1083.

\subsection{Biological Activity against PTP1B and TCPTP}

A colorimetric assay to measure inhibition against PTP1B and TCPTP was performed in 96-well plates. The assay was conducted as described by Zhang et al. [27]. Briefly, the tested compounds were solubilized in DMSO and serially diluted into concentrations for the inhibitory test. The assays were carried out in a final volume of $100 \mathrm{~mL}$ containing $50 \mathrm{mmol} / \mathrm{L}$ MOPS, $\mathrm{pH} 6.5,2 \mathrm{mmol} / \mathrm{L} \mathrm{pNPP}$, $30 \mathrm{nmol} / \mathrm{L}$ GST-PTP1B or GST-TCPTP, and 2\% DMSO, and the catalysis of pNPP was continuously monitored on a SpectraMax 340 microplate reader (Molecular Devices, Sunnyvale, CA, USA) at $405 \mathrm{~nm}$ for $2 \mathrm{~min}$ at $30{ }^{\circ} \mathrm{C}$. The $\mathrm{IC}_{50}$ value was calculated from the nonlinear curve fitting of the percent inhibition [inhibition (\%)] vs. the inhibitor concentration [I] using the following equation:

$$
\text { Inhibition }(\%)=100 /\left[1+\left(\mathrm{IC}_{50} /[\mathrm{I}]\right) \cdot \mathrm{K}\right] \text {, }
$$

where $\mathrm{k}$ is the Hill coefficient.

\subsection{Characterization of Compound $\mathbf{2 9}$}

To determine the mode of inhibition of compound $\mathbf{2 9}$, an assay was carried out in a $100 \mu \mathrm{L}$ assay mixture containing $50 \mathrm{mM}$ MOPS at $\mathrm{pH} 6.5,30 \mathrm{nM}$ PTP1B, pNPP in 2-fold dilution up to $80 \mathrm{mM}$, and different concentrations of inhibitor as described by Zhang et al. [27]. In the presence of the competitive inhibitor, the Michaelis-Menten equation is described as $1 / v=\left(K_{\mathrm{m}} /\left[V_{\max }[\mathrm{S}]\right]\right) \cdot\left(1+[\mathrm{I}] / K_{\mathrm{i}}\right)+1 / V_{\max }$, where $v$ is the initial rate, $V_{\max }$ is the maximum rate, and [S] is the substrate concentration. $K_{\mathrm{i}}$ value was obtained by Lineweaver-Burk plot of apparent $K_{\mathrm{m}} / V_{\max }$ (slope) from primary reciprocal plot versus the inhibitor concentration [I] according to the equation $K_{\mathrm{m}} / V_{\max }=1+[\mathrm{I}] / K_{\mathrm{i}}$.

\section{Conclusions}

In this paper we report a series of stilbene derivatives containing phenyl-substituted isoxazoles as inhibitors against protein tyrosine phosphatase 1B (PTP1B). Most of these compounds 
showed moderate to good inhibitory activity against PTP1B. The most potent compound 29 $\left(\mathrm{IC}_{50}=0.91 \pm 0.33 \mu \mathrm{M}\right)$ showed 14-fold improved PTP1B inhibitory activity compared to the lead compound LCA and about a 4-fold selectivity over TCPTP. Our SAR study clarified the effects of the substituents on the phenyl $\mathrm{C}$ ring on the corresponding activities. Compound 29 was identified as a competitive inhibitor of PTP1B with a $K_{\mathrm{i}}$ value of $0.78 \mu \mathrm{M}$ in enzyme kinetic studies. These novel stilbene derivatives could be promising lead compounds for the development of a new class of PTP1B inhibitors. Further SAR research and evaluation of new derivatives are still in progress.

Supplementary Materials: Supplementary materials can be accessed at: http:/ /www.mdpi.com/1420-3049/21/ $12 / 1722 / \mathrm{s} 1$.

Acknowledgments: This research was financially supported by the Science Fund for Young Scholar of Jiangsu (BK20140425), Initiating Fund for Introduced Talents of Nantong University (03080694), the National Natural Science Foundation of China (81402849), Zhejiang Province Natural Science Foundation (LQ14H300003) and Public Projects of Zhejiang Province (2015C33159 \& 20116C31017). Many thanks to Li Jia's group of National Center for Drug Screening (Shanghai Institute of Materia Medica Academy of Science) for their help in bioassays. We also thank the Analysis \& Testing Centre of Nantong University for support.

Author Contributions: Y.S. designed the research; H.H., J.J., and S.C. performed the research and analyzed the data; Y.G. and F.Y. performed the biological test; H.D. wrote the paper. All authors read and approved the final manuscript.

Conflicts of Interest: The authors declare no conflict of interest.

\section{References}

1. Alonso, A.; Sasin, J.; Bottini, N.; Friedberg, I.; Osterman, A.; Godzik, A.; Hunter, T.; Dixon, J.; Mustelin, T. Protein tyrosine phosphatases in the human genome. Cell 2004, 117, 699-711. [CrossRef] [PubMed]

2. Hunter, T. Signaling-2000 and beyond. Cell 2000, 100, 113-127. [CrossRef]

3. Neel, B.G.; Tonks, N.K. Protein tyrosine phosphatases in signal transduction. Curr. Opin. Cell Biol. 1997, 9, 193-204. [CrossRef]

4. Tonks, N.K. Protein tyrosine phosphatases: From genes, to function, to disease. Nat. Rev. Mol. Cell Biol. 2006, 7, 833-846. [CrossRef] [PubMed]

5. Elchebly, M.; Payette, P.; Michaliszyn, E.; Cromlish, W.; Collins, S.; Loy, A.L.; Normandin, D.; Cheng, A.; Himms-Hagen, J.; Chan, C.C.; et al. Increased insulin sensitivity and obesity resistance in mice lacking the protein tyrosine phosphatase-1B gene. Science 1999, 283, 1544-1548. [CrossRef] [PubMed]

6. Klaman, L.D.; Boss, O.; Peroni, O.D.; Kim, J.K.; Martino, J.L.; Zabolotny, J.M.; Moghal, N.; Lubkin, M.; Kim, Y.B.; Sharpe, A.H.; et al. Increased energy expenditure, decreased adiposity, and tissuc insulin sensitivity in protein-tyrosine phosphatase 1B-deficient mice. Mol. Cell. Biol. 2000, 20, 5479-5489. [CrossRef] [PubMed]

7. Cheng, A.; Uetani, N.; Simoncic, P.D.; Chaubey, V.P.; Lee-Loy, A.; McGlade, C.J.; Kennedy, B.P.; Tremblay, M.L. Attenuation of leptin action and regulation of obesity by protein tyrosine phosphatase 1B. Dev. Cell 2002, 2, 497-503. [CrossRef]

8. Zabolotny, J.M.; Bence-Hanulec, K.K.; Stricker-Krongrad, A.; Haj, F.; Wang, Y.; Minokoshi, Y.; Kim, Y.B.; Elmquist, J.K.; Tartaglia, L.A.; Kahn, B.B.; et al. PTP1B regulates leptin signal transduction in vivo. Dev. Cell 2002, 2, 489-495. [CrossRef]

9. Iversen, L.F.; Moller, K.B.; Pedersen, A.K.; Peters, G.H.; Petersen, A.S.; Andersen, H.S. Structure Determination of T Cell Protein-tyrosine Phosphatase. J. Biol. Chem. 2002, 277, 19982-19990. [CrossRef] [PubMed]

10. Wang, W.L.; Yang, D.L.; Gao, L.X.; Tang, C.L.; Ma, W.P.; Ye, H.H.; Zhang, S.Q.; Zhao, Y.N.; Xu, H.J.; Hu, Z.; et al. 1H-2,3-Dihydroperimidine Derivatives: A New Class of Potent Protein Tyrosine Phosphatase 1B Inhibitors. Molecules 2014, 19, 102-121. [CrossRef] [PubMed]

11. He, H.B.; Gao, L.X.; Deng, Q.F.; Ma, W.P.; Tang, C.L.; Qiu, W.W.; Tang, J.; Li, J.Y.; Li, J.; Yang, F. Synthesis and biological evaluation of 4,4-dimethyl lithocholic acid derivatives as novel inhibitors of protein tyrosine phosphatase 1B. Bioorg. Med. Chem. Lett. 2012, 22, 7237-7242. [CrossRef] [PubMed]

12. Qin, Z.H.; Pandey, N.R.; Zhou, X. Functional properties of Claramine: A novel PTP1B inhibitor and insulin-mimetic compound. Biochem. Biophys. Res. Commun. 2015, 458, 21-27. [CrossRef] [PubMed] 
13. Mitchell, F.R. MSI-1436 reduces acute food intake without affecting dopamine transporter activity. Pharmacol. Biochem. Behav. 2010, 97, 138-143.

14. Dodds, E.C.; Goldberg, L.; Lawson, W.; Robinson, R. Oestrogenic activity of certain synthetic compounds. Nature 1938, 141, 247-248. [CrossRef]

15. Sun, H.M.; Tawa, G.; Wallqvist, A. Classification of scaffold-hopping approaches. Drug Discov. Today 2012, 17, 310-324. [CrossRef] [PubMed]

16. Inamori, Y.; Kato, Y.; Kubo, M.; Yasuda, M.; Baba, K.; Kozawa, M. Physiological activities of 3,3', 4, $5^{\prime}$-tetrahydroxystilbene isolated from the heartwood of Cassia garrettiana CRAIB. Chem. Pharm. Bull. 1984, 32, 213-218. [CrossRef] [PubMed]

17. Belofsky, G.; Percivili, D.; Lewis, K.G.; Tegos, P.; Ekart, J. Phenolic Metabolites of Dalea versicolor that Enhance Antibiotic Activity against Model Pathogenic Bacteria. J. Nat. Prod. 2004, 67, 481-484. [CrossRef] [PubMed]

18. López-Nicolás, J.M.; Rodríguez-Bonilla, P.; García-Carmona, F. Complexation of Pinosylvin, an Analogue of Resveratrol with High Antifungal and Antimicrobial Activity, by Different Types of Cyclodextrins. J. Agric. Food Chem. 2009, 57, 10175-10180. [CrossRef] [PubMed]

19. Bagula, P.K.; Dindab, A.K.; Banerjeea, S.K. Effect of resveratrol on sirtuins expression and cardiac complications in diabetes. Biochem. Biophys. Res. Commun. 2015, 468, 221-227. [CrossRef] [PubMed]

20. Sheng, R.; Xu, Y.; Hu, C.Q.; Zhang, J.; Lin, X.; Li, J.Y.; Yang, B.; He, Q.J.; Hu, Y.Z. Design, synthesis and AChE inhibitory activity of indanone and aurone derivatives. Eur. J. Med. Chem. 2009, 44, 7-17. [CrossRef] [PubMed]

21. Anthony, N.G.; Breen, D.; Clarke, J.; Donoghue, G.; Drummond, A.J.; Ellis, E.M.; Gemmell, C.G.; Helesbeux, J.J.; Hunter, I.S.; Khalaf, A.I.; et al. Antimicrobial Lexitropsins Containing Amide, Amidine, and Alkene Linking Groups. J. Med. Chem. 2007, 50, 6116-6125. [CrossRef] [PubMed]

22. Vallejos, J.C.; Schouteeten, A.; Wilhelm, D. Process for the Synthesis of Polyhydroxystilbene Compounds. US Patent 8,399,714, 23 December 2010.

23. Yamamoto, T.; Fujita, K.; Asari, S.; Chiba, A.; Kataba, Y.; Ohsumi, K.; Ohmuta, N.; Iida, Y.; Ijichi, C.; Iwayama, S.; et al. Synthesis and evaluation of isoxazole derivatives as lysophosphatidic acid (LPA) antagonists. Bioorg. Med. Chem. Lett. 2007, 17, 3736-3740. [CrossRef] [PubMed]

24. Herrero, M.T.; Tellitu, I.; Domínguez, E.; Hernández, S.; Moreno, I.; SanMartín, R. A general and efficient PIFA mediated synthesis of heterocycle-fused quinolinone derivatives. Tetrahedron 2002, 58, 8581-8589. [CrossRef]

25. Ramana, P.V.; Reddy, A.R. Synthesis of 1,2,3-triazole substituted isoxazoles via copper(I) catalyzed cycloaddition. J. Heterocycl. Chem. 2012, 49, 621-627. [CrossRef]

26. Kamal, A.; Tamboli, J.R.; Vishnuvardhan, M.V.; Adil, S.F.; Nayak, V.L.; Ramakrishna, S. Synthesis and anticancer activity of heteroaromatic linked $4 \beta$-amido podophyllotoxins as apoptotic inducing agents. Bioorg. Med. Chem. Lett. 2013, 23, 273-280. [CrossRef] [PubMed]

27. Zhang, W.; Hong, D.; Zhou, Y.; Zhang, Y.; Shen, Q.; Li, J.Y.; Hu, L.H.; Li, J. Ursolic acid and its derivative inhibit protein tyrosine phosphatase $1 \mathrm{~B}$, enhancing insulin receptor phosphorylation and stimulating glucose uptake. Biochim. Biophys. Acta 2006, 1760, 1505-1512. [CrossRef] [PubMed]

Sample Availability: Samples of the compounds 15 30 are available from the authors.

(C) 2016 by the authors; licensee MDPI, Basel, Switzerland. This article is an open access article distributed under the terms and conditions of the Creative Commons Attribution (CC-BY) license (http://creativecommons.org/licenses/by/4.0/). 